\title{
REVISITANDO o IMPASSE EUCLIDIANO À LUZ DO ENSAIO
}

\author{
Revisiting the "Euclidean impasse" in the light of \\ the essay
}

\section{Alfredo Cesar Melo*}

Para João Paulo, pelas tensões sem sínteses

\section{INTRODUÇÃo}

Inspirada pelo Western Canon de Harold Bloom, a Revista Veja (a maior revista do Brasil em número de circulação), na sua edição de 23 de novembro de 1994, juntou um grupo de 15 reconhecidos intelectuais com $o$ objetivo de eleger o "cânone brasileiro". Os Sertóes, escrito por Euclides da Cunha, ficou em primeiro lugar. Com intento semelhante, o jornal $O$ Globo publicou, em 5 de setembro de 1998, uma pesquisa feita entre 10 intelectuais para saber quais seriam os livros mais importantes da literatura brasileira: OS Sertóes figurou em segundo lugar. Por fim, a Folha de S. Paulo, na sua edição de 11 de abril de 1999, publicou uma enquete feita entre vários intelectuais sobre os principais livros de não-ficção já escritos no Brasil, e Os Sertões apareceu em terceiro lugar, atrás apenas de Casa-grande \& senzala de Gilberto Freyre e Raizes do Brasil de Sergio Buarque de Holanda. Apesar do caráter promocional e superficial destas listas, é imperativo notar que as três enquetes convergem para $O S$ Sertóes como obra fundamental do discurso cultural brasileiro.

Acompanhando toda retórica que coloca Os Sertóes no centro do cânone brasileiro, está a afirmação de que a obra principal de Euclides da Cunha é inclassificável, pois transita entre a arte e a ciência, entre a épica

Professor de Literatura Lusófona na Universidade de Chicago 
e a história. A dificuldade de classificar o gênero literário a que Os Sertóes pertence tornou-se um topos da fortuna crítica euclidiana, desencadeando intensos debates sobre o estatuto epistemológico que a obra dispõe.

Os Sertões seria ficção ou história? Seria uma obra de sociologia ou de literatura? Essas são as perguntas mais frequentes nesse debate. $O$ propósito desse artigo é o de revisitar o debate que Leopoldo Bernucci cunhou de "impasse euclidiano" (1995, p. 19). Antes de avançar na nossa análise, a pergunta preliminar que deve ser respondida é: qual seria a relevância de entrar num debate sobre gêneros literários? Não estariam eles fadados a virarem discussões escolásticas, detidas em questões normativas sobre convenções retóricas, de onde se emana mais calor do que luz?

A relevância da discussão é epistemológica: o gênero literário, por meio de suas convenções, indica ao leitor as consequências cognitivas que se pode tirar da obra analisada.

A outra justificativa para retornar-se ao impasse euclidiano seria o de aclarar a semântica de alguns termos importantes, que atualmente se encontram num estado de imprecisão: literatura, ficção, história. Aclarar tais conceitos é um passo fundamental para o avanço da discussão, colocando-a em outros termos que não sejam o da dicotomia entre literatura e ciência. Da maneira que se apresenta, o debate sobre o impasse euclidiano é empobrecedor e não ajuda a entender a obra, nem sua importância na cultura brasileira. Por isso, proponho a moldura do gênero ensaístico para compreender a heterogeneidade discursiva contida na obra de Euclides da Cunha. A meu ver, propor o entendimento de Os Sertóes como pertencente à prática ensaística - uma prática englobadora de tantos discursos e dicções ideológicas na cultura brasileira -, permite sair de uma falsa dicotomia entre literatura e ciência, possibilitando assim que sejam extraídas consequências mais ricas da configuração discursiva da obra.

o nosso ponto de partida será a análise de um dos últimos desenvolvimentos do debate em torno ao impasse euclidiano, que é o estudo de Luiz Costa Lima, Terra ignota, escrito em $1997 .{ }^{1}$

\section{FICÇÃO OU SOCIOLOGIA?}

Para Afrânio Coutinho, Os Sertóes seria um "romance-poemaepopéia"(1967, p. 58), cuja estrutura peculiar tornava a obra de Euclides da Cunha inimitável. Manuel Cavalcanti Proença enxergava na luta entre os

Entre a primeira redação deste artigo e sua efetiva publicação, Luiz Costa Lima publicou seu História. Ficção. Literatura no qual tenta fazer distinções entre estes termos e, mais uma vez, analisa $O S$ Sertóes, ainda que reproduzindo substancialmente seu argumento de Terra ignota. 
brasileiros do litoral e do sertão uma moldura trágica (PROENÇA, 1971, p. 72). Franklin de Oliveira, mesmo ressaltando que a obra de Euclides não era ficção, classifica-a como uma épica (OLIVEIRA, 1983, p. 81). Inconformado com a "permanência da falta de discussão teórico-analítica [...] sobre questão primeira e fundamental: a diferença entre romance e história, entre expressão literária e científica"(LIMA, 1997, p. 19), Luiz Costa Lima, em seu livro Terra ignota, tentará colocar ordem no debate. De acordo com o crítico, o discurso contido em Os Sertôes era predominantemente sociológico (de uma sociologia naturalista, para ser mais específico). Para Costa Lima não havia dúvida de que se tratava de um discurso sobre a realidade, pois a sua construção era baseada num aparato teórico que visava compreender o real. Posto isso, Costa Lima reconhece que havia em Os Sertóes um certo ornamento retórico, uma certa contorção verbal que, no entanto, deixava intocada a estrutura principal do livro - voltada à análise sociológica do sertanejo e dos eventos ocorridos em Canudos (LIMA, 1997, p. 130). O que era considerado literário pelos outros críticos, para Costa Lima não passava de um embelezamento superficial que nada tinha a ver com as verdadeiras potencialidades da literatura, pois o ornamento na obra de Euclides da Cunha estava sempre subordinado ao discurso sociológico.

Se o objetivo de Luiz Costa Lima era limpar o terreno dessa discussão, pode-se dizer que ele logrou um sucesso apenas parcial. Se, por um lado o crítico corretamente enfatiza a predominância do discurso sociológico na obra de Euclides da Cunha, por outro lado o autor de Terra ignota mantém o debate com termos ainda um tanto imprecisos, já que ao longo de livro, Costa Lima usa termos "ficção" e "literatura" indistintamente, como se fossem sinônimos. Faz-se necessário, portanto, destacar a distinção entre esses conceitos - ficção, história, literatura - para dar prosseguimento ao nosso argumento de que os termos do debate a respeito da classificação de Os Sertóes (se é uma obra literária ou científica) estão colocados de uma maneira equivocada.

Como nos mostram Peter Lamarque e Stein Olsen, em Truth, Fiction and Literature, a grande distinção entre ficção e história (ou sociologia) não passa por nenhum imanentismo textual - nenhuma propriedade inerente ao texto - mas é marcada por práticas sociais diferentes (1994, p. 30-39). Essas práticas sociais engendram pactos tácitos entre os seus participantes. Em outras palavras, quando um autor escreve um livro de história (ou sociologia), está se submetendo a um pacto com o leitor que é bem distinto daquele que um escritor de ficção se submete quando escreve um romance. O historiador (ou sociólogo) tem a pretensão de escrever um discurso sobre a realidade no qual ele reivindica estar realizando uma representação acurada e correspondente dessa realidade, e que tal representação está baseada em 
algumas evidências que podem ser checadas e contestadas. As afirmações contidas num livro de história (ou de sociologia) podem ser julgadas como falsas ou verdadeiras pela comunidade de historiadores. Já um escritor de ficção, por sua vez, não precisa reivindicar para seu discurso nenhuma correspondência com a realidade, nem necessita basear suas afirmações em nenhuma evidência. A expectativa que estabelece com o leitor é outra e passa pelo pacto imaginativo da suspensão de crença e da semântica do fazer-de-conta. Para voltar ao impasse euclidiano, se levarmos em conta os pactos criados por essas diferentes práticas de narração, torna-se claro que o propósito de Euclides da Cunha ao escrever Os Sertóes, não era produzir uma obra ficcional. Afinal, quando lançada a obra em 1902, as duas pontas da dinâmica literária - escritor e leitor - estavam muito cientes de qual era o referencial de Os Sertóes: livro que apontava para uma questão nacional e que, como tal, deveria ser discutida. O impacto ético do livro deriva de sua dimensão interpeladora, isto é, de sua relação com a realidade. A obra de Euclides da Cunha conclama os brasileiros a examinarem o que ocorreu em Canudos e a avaliar a ação do Brasil "civilizado" do litoral. Isto dito, afirmar que Os Sertóes é um discurso sobre a realidade - construído com a moldura analítica da sociologia naturalista do século 19 - não é dizer muito sobre o livro. Não explica a importância que o livro veio a ter na história cultural e literária do Brasil. Afinal, como obra sociológica, Os Sertões é um livro inequivocamente datado. Se é certo dizer que Os Sertóes dispõe de um discurso eminentemente sociológico, como sugere Costa Lima, também é correto afirmar que atualmente essa obra oferece uma explicação sociológica falha, que não é mais reconhecida dentro da prática vigente da produção de trabalhos sociológicos na comunidade intelectual. o que explicaria o fato de que um livro completamente anacrônico do ponto de vista de sua interpretação sociológica estar no centro do cânone brasileiro? Por que, depois de tantos anos, os intelectuais brasileiros se voltam para uma obra que contém um embotado discurso sociológico para afirmar que tal obra é representativa de seus dilemas e problemas?

Embora a ênfase de Costa Lima na predominância do discurso sociológico seja correta, ela não nos ajuda a compreender o lugar de $O S$ Sertóes no campo discursivo brasileiro. Para isso, propomos uma outra estratégia de entendimento da obra de Euclides da Cunha - que passa pelo gênero ensaístico. 


\section{ENSAIO}

Numa das páginas luminares de Literatura e sociedade, Antonio Candido escreve sobre o ensaísmo no Brasil, forma literária que ele considera como uma das mais originais do pensamento brasileiro:

O poderoso imã da literatura interferia com a tendência sociológica, dando origem àquele gênero misto de ensaio, construído na confluência da história com economia, a filosofia ou a arte, que é uma forma bem brasileira de investigação e descoberta do Brasil e à qual devemos a pouco literária História da literatura brasileira, de Silvio Romero, Os Sertões, de Euclides da Cunha, Populações meridionais do Brasil de Oliveira Viana, a obra de Gilberto Freyre e Raízes do Brasil de Sérgio Buarque de Holanda. Não será exagerado afirmar que esta linha de ensaio - em que se combinam com felicidade maior ou menor a imaginação e observação, a ciência e a arte - constitui o traço mais característico e original de nosso pensamento. (2000, p.119)

Infelizmente Antonio Candido não desenvolveu uma reflexão mais sistemática sobre esse gênero que o próprio crítico considerou como o "traço mais característico e original do nosso pensamento". No entanto, a citação de Candido pode nos servir como bom ponto de partida para uma caracterização do ensaio enquanto gênero literário - ou prática do campo intelectual brasileiro.

Como aponta Candido, o ensaio constituiu uma forma de investigação bastante interessada sobre o Brasil. Ela se manisfestava sob a moldura da afirmação de um projeto nacional. 0 ensaio brasileiro continha tanto uma instância explicativa como uma instância propositiva. Era preciso conhecer a realidade brasileira para propor as resoluções dos imbróglios da nação. Para isso, fazia-se necessário mobilizar todo tipo de conhecimento da época, que devido ao precário estado institucional do campo intelectual brasileiro, era recebido com certa dose de ecletismo ${ }^{2}$.

\footnotetext{
Os fundamentos institucionais do ensaio brasileiro e seu ecletismo são diferentes daqueles do ensaísmo hispano-americano. Na América Hispânica, o ecletismo do ensaio se dava pela resistência dos intelectuais a se submeterem à "pureza" de um discurso especializado. De acordo com Julio Ramos, intelectuais como José Martí enxergavam na especialização do discurso uma faceta alienante da divisão do trabalho, e exerciam essa crítica em nome de uma defesa da integridade "humana" (2001 p. 232), embora paradoxalmente inserissem essa crítica numa mídia especializada, como o jornal. No caso brasileiro, intelectuais como Euclides da Cunha e Silvio Romero de fato queriam ser científicos. As fissuras de seu discurso científico não se dão por uma estratégia deliberada em criticar a especialidade desse discurso, mas ocorrem a contrapelo. Como pontua Roberto Schwarz, "a fratura da forma aponta para impasses históricos" (2000, p. 171). Esse artigo busca entender a relação entre fratura do ensaísmo brasileiro e seus correspondentes impasses históricos.
} 
Não é raro encontrar num mesmo texto da tradição ensaística brasileira exemplos dessas duas instâncias mencionadas. Vejamos dois trechos de Estudos sobre a poesia popular do Brasil de Silvio Romero. No primeiro trecho, Romero faz um diagnóstico do que seria a cultura brasileira, à luz das teorias racistas tão caras ao seu esquema intelectual:

\begin{abstract}
Povo que descendemos de um estragado e corrupto ramo da velha raça latina, a que juntara-se o concurso das velhas raças mais degradadas do globo, os negros da costa e os peles-vermelhas da América, nós ainda não nos distinguimos por uma só qualidade digna de apreço [. . .] O servilismo do negro, a preguiça do índio e o gênio tacanho e autoritário do português produziram uma nação informe, sem qualidades fecundas e originais. (1977, p. 266, grifos do autor)
\end{abstract}

O trecho é rico porque nele Romero reproduz todos os estereótipos racistas que à época tinham verniz científico. Apesar desses juízos atualmente serem lidos apenas como lixo ideológico, não se deve perder de vista que Romero pensava estar fazendo um diagnóstico impiedoso da cultura brasileira, tendo em mão a melhor ciência que ele supunha dispor a seu alcance. No entanto, isso não impede que, ao final de seu ensaio, ele mude substancialmente de perspectiva, adotando o seguinte tom:

\begin{abstract}
o papel histórico das três raças está mais ou menos cumprido: o português deu-nos sangue, a língua e a tal ou qual cultura que possuímos, o índio deu-nos também o seu sangue, suas terras e em parte suas tradições, o negro deu-nos ainda o seu sangue, seu trabalho, sua força, sua vida! Todos cumpriram mais ou menos o seu dever. Cumpramos também o nosso. O nosso dever de brasileiros, de filhos dos três povos que nos entregaram o país descoberto, conhecido, povoado, autonômico e livre (1977, p. 272, grifos do autor).
\end{abstract}

Neste último trecho está clara a instância propositiva do nationbuilding operando como princípio organizador. Mesmo diante de um diagnóstico desolador, Romero empenha-se em criar uma retórica nacionalista, que conclama os outros brasileiros a construção de uma nação que ainda estava por se fazer.

Constata-se, portanto, que o ensaísmo brasileiro, na sua versão oitocentista e da Belle Époque, moveu-se nesse morde-assopra que era conhecer o Brasil a partir de teorias racistas, inevitavelmente detratoras da cultura híbrida brasileira, ao mesmo tempo em que também se propunha a 
vislumbrar uma dignidade civilizatória para a nação em construção ${ }^{3}$.

É preciso entender o gênero ensaístico dentro de suas condições de possibilidade. Como afirma o historiador José Murilo de Carvalho, o excesso de referência à autoridade científica estrangeira se explicava pela ausência de prática de investigação científica no Brasil, o que levava os argumentos contidos nos ensaios e tratados produzidos no país a buscar uma fundamentação livresca, em vez de empírica (1998, p.25). O que não impedia que trabalhos embasados em alguma prestigiosa teoria científica - geralmente racista - tivessem suas próprias premissas teóricas solapadas ou contraditadas por observações ou narrativas concretas desses mesmos intelectuais. ${ }^{4} \mathrm{O}$ caso de Euclides da Cunha é paradigmático, mas há outros exemplos na tradição ensaísta brasileira, como o de Gilberto Freyre; capaz de, no mesmo texto, Casa-grande \& senzala, defender teorias de harmonização social, e narrar, com riquíssimos detalhes, a violência sistemática que permeava a sociedade patriarcal. O ensaio é, portanto, um texto que convida o estudo das aporias, das fissuras, das disjunções e descontinuidades ideológicas. O ensaio é a forma que expõe a fratura de um país a se completar, na medida em que internaliza as tensões, produzidas pelas deficiências institucionais, entre os discursos literários e científicos, cada um a seu modo, também incompletos e heterônomos em solo brasileiro.

\section{Os SERTões: Ensaísmo Na SuA Tensão Máxima}

Os Sertões de Euclides da Cunha talvez tenha sido a mais bem acabada realização dessa prática discursiva ideologicamente heterogênea que foi o ensaísmo brasileiro do século XIX e início do século XX (da fase pré-Gilberto Freyre). Como bem observaram Nicolau Sevcenko (1983, p.133), Leopoldo Bernucci (1995, p. 23) e Roberto Ventura (2005a, p. 112), Euclides da Cunha era um intelectual dividido entre o romantismo desabrido de Victor Hugo e Alfredo Musset e o naturalismo radical de Louis Gumplowics. Por meio de seu romantismo, o autor de Os Sertóes irá heroicizar o sertanejo (semente do projeto de nação euclidiano), enquanto munido de seu

Não queremos dizer com isso que o paradigma racial tenha sido o único existente no campo cultural brasileiro do tardo oitocentos. Este paradigma certamente foi o hegemônico, pois como documenta Lilia Schwartz, era reproduzido nas academias de direito e medicina do Brasil. No entanto, intelectuais como Manoel Bonfim, Oliveira Lima e Joaquim Nabuco escreveram suas obras sem necessariamente cair nos impasses das teorias raciais. Para uma análise de cada um desses respectivos ensaístas, verificar Ventura (2003b), Lima (2003) e Mello (2002).

Em artigo recente sobre Euclides da Cunha, João Cezar de Castro Rocha tenta resgatar no autor de OS Sertóes a figura do theoros. O theoros seria aquele que "observa e contempla". Para Castro Rocha, Euclides seria o theoros que se insurgiu contra a teoria de sua época (ROCHA, 2004, p. 156). 
naturalismo, condenará o atraso atávico das populações sertanejas. Servindo-se de tamanho espectro ideológico, Euclides da Cunha seria o escritor que poderia levar ao limite as tensões que alimentavam o gênero ensaístico brasileiro no século XIX.

O autor de frases tão celebradas na cultura brasileira - "o sertanejo é antes de tudo um forte" (CUNHA, 2002, p.207), "rocha viva da nacionalidade" (2002, p. 788) - será o mesmo que julgará o povo sertanejo, à luz de sua antropologia evolucionista, como atrasado, retrógrado e bárbaro. Apesar de parecerem enunciados contraditórios, encontram-se em perfeita coerência com a lógica interna do pensamento euclidiano.

Vimos acima que a situação do imbróglio ideológico do ensaísmo brasileiro da Belle Époque era a seguinte: de um lado, fundamentava suas análises em teorias raciais que condenavam a miscigenação. Ou seja, pelo prisma de tais teorias raciais, o Brasil seria um país inviável. Do outro lado, a grande maioria dos intelectuais brasileiros envolvidos na questão racial estava imbuída da ética do nation-building. Como nos mostra o estudo de Lilia Schwartz, para lidar com tais contradições, muitos intelectuais fizeram adaptações de tais teorias raciais para que pudessem acalentar alguma viabilidade para o projeto nacional (SCHWARTZ, 1993, p. 19). Com Euclides da Cunha não foi diferente. Segundo o autor de Os Sertões, por ser o sertanejo um povo mestiço que há muito tempo estava isolado no interior do Brasil, sem contatos e misturas com as populações litorâneas, haveria para este povo racialmente mais estável uma possibilidade de vir a se tornar a raça brasileira por excelência. Como comenta Euclides a respeito da "raça" sertaneja:

\begin{abstract}
A sua evolução psíquica, por mais demorada que esteja destinada a ser, tem, agora, a garantia de um tipo fisicamente constituído e forte. Aquela raça cruzada surge autônoma e de algum modo, original, transfigurando, pela própria combinação, todos atributos herdados, de sorte que, despeada afinal da existência selvagem, pode alcançar a vida civilizada por isto mesmo que não atingiu de repente $[\ldots .].[\mathrm{N}]$ os sertões a integridade orgânica do mestiço desponta inteiriça e robusta, imune de estranhas mesclas, capaz de evolver, difereciando-se, acomodando-se a novos e mais altos destinos, porque é a sólida base física do desenvolvimento moral ulterior.(2002, p. 103, grifos meus)
\end{abstract}

O ensaio de Euclides da Cunha será marcado por um "senso de possibilidade" que seu aporte teórico adaptado vislumbrava no sertanejo. Tal senso de possibilidade representava uma brecha no edifício teórico racista, 
capaz de engendrar, no texto euclidiano, uma retórica da transfiguração ${ }^{5}$. Como se pode ver em famoso trecho de Os sertóes:

[O sertanejo é] desgracioso, desengonçado, torto. HérculesQuasímodo, reflete no aspecto a fealdade típica dos fracos. $\mathrm{O}$ andar sem firmeza, sem aprumo, quase gigante e sinuoso, aparenta a translação de membros desarticulados... É o homem permanentemente fatigado... Reflete a preguiça invencível, a atonia muscular em tudo.[...] Entretanto, toda esta aparência de cansaço ilude.[...]Basta o aparecimento de qualquer incidente exigindolhe o desencadear das energias adormecidas. O homem transfigura-se. Empertiga-se, estadeando novos relevos, novas linhas na estatura e no gesto, e a cabeça firma-se-lhe, alta, sobre os ombros possantes, aclarada pelo olhar desassombrado e forte, $\mathrm{e}$ corrigem-se-lhes, prestes, numa descarga nervosa instantânea, todos os efeitos do relaxamento habitual dos órgãos, e da figura vulgar do tabaréu canhestro, reponta, inesperadamente, o aspecto dominador de um titã acobreado e potente, num desdobramento surpreendente de força e agilidade extraordinárias. (CUNHA, 2002, p. 208, grifos meus)

o que se pode constatar nesse trecho é o condensamento de todas as linhas de força ideológicas de Euclides da Cunha: o vocabulário naturalista, indicando a fraqueza de uma sub-raça, a enaltação romântica do heroísmo sertanejo, e a metáfora classicista - o sertanejo como titã. Todo esse repertório de dicções é mobilizado para representar a transfiguração do sertanejo, e mostrar as potencialidades de uma raça cuja grandeza encontrava-se adormecida - mas que, por um ínfimo lampejo, tal grandeza poderia ser entrevista através de alguns gestos do sertanejo.

Por meio dessa retórica da transfiguração, Euclides da Cunha conseguia vislumbrar um tipo de viabilidade - ainda que muito em potencial - para a cultura brasileira. Ademais, ao criar metáforas greco-latinas para medir e avaliar a ação dos sertanejos, Euclides da Cunha retomava a tradição neoclássica brasileira, fartamente estudada por Antonio Candido em sua Formação da literatura brasileira, de conectar o local à tradição ocidental.

Antonio Candido, em artigo sobre Euclides da Cunha na década de 40, enfatiza a diferença entre o esquema intelectual criado por Euclides - onde a transfiguração é possível - e as teorias racistas européias: "O homem euclideano é o homem guiado pelas forças telúricas, engolfado na vertigem das correntes coletivas, garroteado pelas determinações biopsíquicas: - e, no entanto, elevando-se para pelejar e compor a vida na confluências destas fatalidades. Semelhante visão não se confunde com o mecanismo de muitos deterministas do seu tempo ou anteriores a ele. Em Ratzel, ou em Buckle, não há tragédia: há jogo mútuo quase mecânico entre homem e meio" (2002, p. 181-182). Por sua vez, Dain Borges argumenta que há em Os Sertóes uma verdadeira obsessão pelo tema da transfiguração, o que viria a ser uma fissura na retórica determinista adotada pela sociologia naturalista do final do seculo XIX. 
Através dessa conexão, operada pela metáfora greco-latina, Euclides tentava transmitir uma certa dignidade "civilizatória" para a população sertaneja ${ }^{6}$. Outro exemplo da retórica da transfiguração seria a famosa cena do enforcamento de um sertanejo em Canudos. O sertanejo é descrito como animal ("um orango valetudinário"), e ao longo da cena, devido a sua atitude brava e altiva, transforma-se numa "velha estátua de titã, soterrada havia quatro séculos e aflorando, denegrida e multilada, naquela imensa ruinaria de Canudos"(CUNHA, 2002, p.732).

Um negro, um dos raros negros puros que ali havia, preso em fins de setembro, foi conduzido à presença do comandante da $1 .^{\mathrm{a}}$ coluna, general João da Silva Barbosa. Chegou arfando, exausto da marcha aos encontrões e do recontro em que fora colhido. Era espigado e seco. Delatava na organização desfibrada os rigores da fome e do combate. A magreza alongara-lhe o porte, ligeiramente curvo. A grenha, demasiadamente crescida, afogava-lhe a fronte estreita e fugitiva; e o rosto, onde o prognatismo se acentuara, desaparecia na lanugem espessa da barba, feito uma máscara amarrotada e imunda. Chegou em cambaleios. $O$ passo claudicante e infirme, a cabeça lanzuda, a cara exígua, um nariz chato sobre lábios grossos, entreabertos pelos dentes oblíquos e saltados, os olhos pequeninos, luzindo vivamente dentro das órbitas profundas, os longos braços desnudos, oscilando - davam-lhe a aparência rebarbativa de um orango valetudinário.

Não transpôs a couceira da tenda.

Era um animal. Não valia a pena interrogá-lo

o general de brigada João da Silva Barbosa, da rede em que convalescia de ferimento recente, fez um gesto. Um cabo de esquadra, empregado na comissão de engenharia e famoso naquelas façanhas, adivinhou-lhe o intento. Achegou-se com o braço. Diminuto na altura, entretanto, custou a enleá-lo ao pescoço do condenado. Este, porém, auxiliou-o tranqüilamente; desceu o nó embaralhado; enfiou-o pelas próprias mãos, jugulando-se. . . $[\ldots]$ E viram transmudar-se o infeliz, apenas dados os primeiros passos para o suplício. Daquele arcabouço denegrido e repugnante, mal soerguido nas longas pernas murchas, despontaram, repentinamente, linhas admiráveis - terrivelmente esculturais

Em Formação da literatura brasileira, Antonio Candido estuda o neoclássico no Brasil como um período de tentativa de integração simbólica da América à tradição literária e imagética do Ocidente. Segundo Candido "talvez seja possível, mesmo, afirmar que a vituperada quinquilharia clássica tenha sido, no Brasil, excelente e proveitoso fator de integração cultural, estreitando com a cultura do ocidente a nossa comunhão de coloniais mestiçados, atirados na aventura de plasmar no trópico uma sociedade em molde europeu. (77). Embora Euclides seja um escritor do século XX, a constante comparação do povo sertanejo com o imaginário grego-latino também pode ser procedimento semelhante àquele dos neoclássicos. 
- de uma plástica estupenda.

Um primor de estatuária modelado em lama.

Retificara-se de súbito a envergadura abatida do negro aprumandose, vertical e rígida, numa bela atitude singularmente altiva. A cabeça firmou-se-lhe sobre os ombros, que se retraíram dilatando o peito, alçada num gesto desafiador de sobranceria fidalga, e o olhar, num lampejo varonil, iluminou-lhe a fronte. Seguiu impassivel e firme; mudo, a face imóvel a musculatura gasta duramente em relevo sobre os ossos, num desempenho impecável, feito uma estátua, uma velha estátua de titã, soterrada havia quatro séculos aflorando, denegrida e mutilada, naquela imensa ruinaria de Canudos. Era uma inversão de papéis. Uma antinomia vergonhosa (CUNHA, 2002, p.732, grifos meus)

O trecho é particularmente interessante, não só porque permite entrever a retórica da transfiguração operando, mas também porque, dessa vez, um "negro puro" é narrativizado dentro da moldura greco-latina. Se antes Euclides depositava sua esperança no povo sertanejo por um critério meramente étnico - devido ao isolamento geográfico, o sertanejo havia se tornado uma raça estável -, nesse caso, o que faz o negro ser digno de louvor não é o fato de ser "etnicamente" um sertanejo, mas de ter participado na luta com altivez e honra. $\mathrm{O}$ fator étnico cede espaço para o aspecto ético. E no decorrer da narrativa, a transição é evidente. No primeiro parágrafo, a descrição física do negro é toda ela marcada pelo vocabulário naturalista. A comparação com o orango valetudinário dá o tom racista da descrição. Acabada a descrição física, Euclides parte para a narrativa do evento e aí os sinais de inferioridade e superioridade se invertem, a começar pelo próprio fato da execução do "animal" ter sido sumária, sem julgamento por parte dos "civilizados". Mas o negro é todo ele altivo e sóbrio e se agiganta moralmente diante daquela situação, realçada pela ironia do condenado ajudar o soldado de baixa estatura colocar a corda em seu pescoço. 0 contraste entre $o$ alto e o baixo, entre $o$ ar altaneiro do condenado e o gesto hesitante do soldado encenam a inversão de papéis que seriam esperados do "civilizado" e do "bárbaro". Então se inicia a transfiguração: da "ruinaria" de Canudos, emerge a estátua de titã. Da lama, surge a beleza de um povo resistente. Esse jogo de antinomias produz uma dinâmica de reversibilidade que antecipam a prosa rosiana. Outra metáfora importante no trecho é a geológica: a do soterramento. A estátua de titã encontrava soterrada pela ruinaria, pelas camadas de barbárie. Mas ainda que enlameada, a estátua não deixava de ser bela. o potencial do povo brasileiro encontrava-se adormecido e soterrado por camadas de ignorância, barbárie e malentendidos históricos.

É importante notar como o ângulo de Euclides muda, ao longo da 
cena apontada, mostrando a tensão entre retórica naturalista com verniz científico e enaltação imaginativa por meio de metáforas greco-latinas. $\mathrm{O}$ ímpeto de registrar a realidade coexiste com o desejo de imaginar alternativas possíveis dentro daquela realidade, de investigar virtualidades - o titã soterrado - dentro do quadro descrito. Há momentos de sociologia naturalista, e momentos de épica sem, no entanto podermos reduzir o texto a uma dessas classificações É essa tensão e essa heterogeneidade de tons e registros que marcam o ensaio.

\section{OS SERTÕES: LITERATURA?}

É importante descrever como o ensaísmo brasileiro funcionava, e como Euclides da Cunha movia-se dentro do horizonte dessa tradição ensaística, porque entendendo a função do ensaísmo na esfera pública brasileira, com suas instâncias explicativas e propositivas, podemos encaminhar uma questão importante do impasse euclidiano: Por que $O S$ sertões seria uma obra literária? Vimos anteriormente que Luiz Costa Lima, em seu Terra ignota, havia embaralhado os termos "ficção" com o de "literatura", para então concluir que OS Sertóes não era um obra literária, dado que a obra não era ficcional. Se ficção é definida por um pacto entre escritor e público que passa pela suspensão da descrença e pela semântica do fazer de conta, a literatura é um conceito de natureza completamente distinto. Como lembra John Searle (1975, p.321), literatura é um conceito valorativo (evaluative concept). A fronteira entre literatura e não-literatura é decidida por meio das lutas e tomadas de posição no campo literário (BOURDIEU, 1996, p. 261-263). Cabe à comunidade de leitores decidir que tipo de texto deve ou não ser considerado literatura. Livros como a Bíblia, ou The History and Decline of the Roman Empire de Edward Gibbon, ou a biografia de Samuel Johnson escrita por James Boswell são todos considerados obras literárias pelas comunidades de leitores nas quais essas obras circulam. No que diz respeito a Os sertóes, não é preciso relembrar do prestígio imediato que a obra virá a dispor no campo cultural brasileiro, obtendo uma canonização sem precedentes na história cultural brasileira. A hipótese que pretendo desenvolver é que Os Sertóes só conquistou o lugar tão proeminente na cultura brasileira porque se inseriu numa prática discursiva - a ensaística -, que no campo cultural do Brasil tinha funções muito além das investigativas ou científicas. Articulando sociologia naturalista, empenho nacionalista e uma retórica da transfiguração, Euclides encontrou no espaço possível do ensaísmo brasileiro uma maneira de conclamar um debate nacional, apresentando dilemas e discutindo possíveis 
soluções. A obra de Euclides não sobrevive hoje pelo seu discurso sociológico, mas pelo seu gesto propositivo de, mobilizando um arsenal retórico que vai do cientificismo às metáforas greco-latinas, repensar os fundamentos e o contrato social da nação. Os Sertóes passou a ser não só um modelo de retórica, mas de civismo. Essa posição seria impensável, se não levarmos em conta a pragmática do gênero ensaístico, que ao mesmo tempo em que explica, interpela.

o meu argumento passa a ser mais bem compreendido quando se compara Os Sertóes às outras obras escritas sobre o evento de Canudos. Regina de Abreu, estudiosa do processo de canonização da obra euclidiana, afirma em seu livro $O$ Enigma de os Sertões que havia uma imensa quantidade de publicações em torno do acontecimento de Canudos anteriores a Os Sertões (1998, p.161-164). Euclides da Cunha não foi o primeiro a criticar a condução da campanha do exército. Antes dele o fizera o então tenente-coronel Dantas Barreto, que havia comandado uma das brigadas da expedição e que em 1898 publicou seu livro, a Última expedição a Canudos.

Euclides da Cunha também não foi o primeiro a denunciar a violência desnecessária usada contra os sertanejos. O estudante de medicina, Alvim Martins Horcades, publicou em 1899 a descrição de sua viagem a Canudos em que denuncia degolamentos de jagunços.

Seguindo a mesma linha de raciocínio podemos dizer que Euclides não foi o primeiro autor que poetizou o sertanejo a partir desse conflito. Outro estudante de medicina, chamado Francisco Mangabeira, publicou, em 1900, um livro poético sobre os acontecimentos de Canudos, ao qual deu o título de Tragédia épica.

Por fim, pode-se dizer que também não fora Euclides o autor a interpretar o ocorrido em Canudos com um referencial teórico cientificista. Logo após o final da Guerra, Nina Rodrigues publica na Revista Brasileira um artigo chamado "A Loucura Epidêmica de Canudos", no qual diagnostica a "psicose sistemática progressiva" do Conselheiro, que sofria também de "delírio crônico". O próprio Nina Rodrigues chegou a analisar o crânio do Conselheiro e embora o considerasse um "crânio normal", confirmou seu diagnóstico de "delírio crônico".

Nenhum deles, no entanto, conseguiu coordenar tantas perspectivas, para falar de Canudos como uma "variante de assunto geral" (CUNHA, 2002, p. 13), que era a questão nacional. Daí poder-se concluir que OS Sertões tem hoje uma dimensão eminentemente monumental na cultura brasileira. Por monumental, refiro-me ao sentido etimológico da palavra monumento que quer dizer "aquilo que traz a memória, a lembrança". Como aponta Benedict Anderson, no último capítulo de seu Imagined Communities, seria através da construção de uma política da 
memória - forjada na dialética entre lembrança e esquecimento - que as nações seriam capazes de superar os traumas das cizânias e das violentas lutas internas. Narrativizando tais disputas como "fratricídio" , o discurso nacionalista "relembrava" o evento com o luto pelas vidas patriotas que se perderam, ao mesmo tempo que "esquece" as pretensões separatistas ou exclusivistas desse grupos que, à sua época, jamais imaginaram que poderiam coexistir no panteão da memória nacional (1991, p. 190).

Ao apontar para o fratricídio, para a luta entre compatriotas, Euclides aponta para a ruína de uma unidade nacional que só existiu na retórica dos políticos. E ao denunciar a falta de comunicação entre a civilização do litoral e a raça sertaneja, denuncia um abismo que é impedidor de qualquer possibilidade de nação: para Euclides da Cunha, o sertanejo nunca desenvolverá suas potencialidades se não for integrado à civilização, enquanto os brasileiros do litoral nunca terão uma civilização de verdade se não se derem conta da importância do interior do Brasil e do sertanejo como raça verdadeiramente brasileira.

E mais do que denunciar o abismo entre classes no Brasil, Euclides da Cunha e sua opus magnum estabeleceram as disposições do intelectual brasileiro no século XX. Isso pode ser visto na "Nota Preliminar" de OS Sertóes, em que Euclides trata do narrador sincero, citado por Taine:

[O narrador sincero] se irrita contra as semi-verdades, que são semi-falsidades, contra os autores que guardam o desenho dos acontecimentos e modificam a sua cor, que copiam os fatos e desfiguram a alma: ele quer se sentir como bárbaro entre os bárbaros, e entre os antigos como antigo (TAINE apud CUNHA, 2002, p. 67). ${ }^{7}$

Esse trecho condensa duas disposições que orientaram o trabalho de Euclides da Cunha e continuariam orientando o intelectual brasileiro ao longo do século XX: a sinceridade e a empatia. Seriam, respectivamente, uma disposição "epistemológica" e a outra "ética". A sinceridade seria uma maneira de descrever a realidade, buscando sempre a maior precisão e acuidade. A empatia, como a que Euclides exibe pelos sertanejos, guiaria o narrador sincero a servir ao lado certo da questão: o lado do povo. O exemplo que demos sobre o "negro puro" enforcado em Canudos mostra como, no início da cena, a tentativa de descrever precisamente a situação, com os termos técnicos de uma ciência racista, cede gradualmente espaço para a

A tradução para o português é de Berthold Zilly (ZILLY, 2001, p. 300). Euclides cita o texto no original, em francês: "Il s' irrite contre les demi vérités que sont des demi faussetés, contre les auteurs qui n’altèrent ni une date, ni une généalogie, mais dénaturent les sentiments et les moeurs, qui gardent le dessin des événements et en changent la couleur, qui copient les faits et défigurent l'âme; il veut sentir en barbare, parmi les barbares, et, parmi les anciens, en ancien." 
tomada de posição do narrador pelo condenado. Se antes, o escritor se atinha a um registro mais aderente possível ao real, no segundo momento, tornase mais imaginativo, abandonando a linguagem denotativa, e abraçando as metáforas e a linguagem mais conotativa.

Euclides da Cunha poderia ser considerado o pródromo do nacionalpopular, pois tal paradigma tem como alicerce, na palavra de um de seus principais ideólogos, Carlos Nelson Coutinho, a aliança entre o intelectual e o povo (COUTINHO, 2000, p. 62). A ânsia em representar fielmente seja a realidade opressiva, ou os potenciais revolucionários do povo, e a empatia pela causa popular formam o núcleo desse pacto.

Inúmeros são os exemplos de produções culturais orientadas por essas balizas. O negro no ensaio de Gilberto Freyre (Casa-grande \& senzala), o moleque do eito na ficção de José Lins do Rêgo ( $O$ moleque Ricardo), o retirante nas obras de Graciliano Ramos e João Cabral de Melo (Vidas secas e Morte e vida severina), o operário urbano, o camponês das plantações de cacau, a criança marginal nos romances de Jorge Amado Jubiabá, Cacau, Capitães de areia) poderiam ser citados como representações do povo baseadas nessa disposição "sincera" de alertar sobre uma realidade, e na solidariedade, ou empatia, em relação aos mais excluídos e oprimidos.

Pode-se dizer que desde a Independência, os intelectuais brasileiros se sentiram imbuídos da missão de construir simbolicamente a nação, isto é, de exaltar suas virtudes, sua geografia, sua diversidade regional. José de Alencar seria o exemplo mais bem acabado desse sentido de missão no século XIX. Mas foi Euclides da Cunha que adicionou o pathos a essa missão, imprimindo um senso de urgência para uma possível solução, apontando para as terríveis desigualdades, e denunciando a alienação do povo brasileiro em relação ao mundo moderno e a esfera da cidadania.

Os Sertões não teria tanto sucesso, conquistando corações e mentes, se fosse um tratado de sociologia naturalista, escrito por um especialista. Também não teria o mesmo alcance ético, se fosse apenas obra imaginativa, sem se referir à realidade concreta do país. Num país onde nem a ciência nem a literatura haviam atingido um grau razoável de autonomia, o livro de Euclides tentou abarcar os dois discursos. E se Os Sertóes é sobre a fragmentação da nação e a falta de diálogo entre os seus membros, o ensaio de Euclides da Cunha é, na sua própria forma, uma maneira de superar a fragmentação discursiva e buscar o diálogo e interações possíveis entre os discursos à sua disposição. Talvez por ser ao mesmo tempo sintoma e tentativa de superação do subdesenvolvimento intelectual, o ensaio constitua o traço mais original do pensamento brasileiro. 


\title{
RESUMO
}

O presente artigo pretende retomar o "impasse euclidiano" sobre o gênero literário de Os sertóes. Argumento que os termos do debate - sobre a obra de Euclides ser uma obra de literatura ou ciência, de ficção ou sociologia - estão equivocados e que o entendimento sobre o gênero literário a que Os Sertóes pertence ganha mais clareza quando se discute o ensaísmo na cultura brasileira. O ensaio foi o gênero por excelência da esfera pública brasileira no final do século XIX e início do século XX, quando as universidades não existiam e a literatura ainda desempenhava papel central na cultura brasileira. O ensaio, fundindo ciência mal digerida com imaginação literária, mobilizava várias dicções ideológicas, estilos e abordagens de muitas disciplinas para conhecer novos aspectos da realidade nacional (dimensão cognitiva) e invocar a resolução dos problemas identificados (dimensão propositiva). Sem ser uma obra que se filie à ciência ou à ficção, Os sertões faz uso dessas instâncias para interpelar o leitor a re-examinar as premissas da nacionalidade. A pragmática da obra se baseia nesse apelo interpelador, que é a principal função do ensaio na cultura brasileira. $\mathrm{O}$ artigo conclui que a dicotomia classificatória entre literatura e ciência é insatisfatória para entender o alcance que o livro de Euclides da Cunha tem na cultura brasileira e pretende compreender esse alcance por meio da discussão do ensaio.

Palavras-chave: Ensaísmo; Euclides da Cunha; Os Sertões.

\begin{abstract}
This current paper intends to readdress the "Euclidean impasse" about Rebellion in the Backlands' literary genre. I argue that the key terms of this debate (if Rebellion in the Backlands would be a work of science or literature, sociology or fiction) are formulated resorting to the wrong theoretical framework. I also contend that the understanding of the literary genre to which Rebellion in the Backlands pertains will become more clear when the essay enters into the forefront of the debate. The essay was the most original genre of Brazilian public sphere throughout the end of $19^{\text {th }}$ century and the beginning of $20^{\text {th }}$ century, when there were no universities and literature still played a central role in Brazilian culture. The essay, mixing an eclectic use of science and literary imagination, mobilized many dictions, styles and a plethora of scientific disciplines in order to undertake a new approach on Brazilian reality (the
\end{abstract}


cognitive dimension) and invoke Brazilians to solve the problems of the Nation (the proposing dimension). Although it cannot be considered a work of neither science nor fiction, Rebellion in the Backlands employs those instances to interpellate Brazilians to reexamine the core of nationality. The pragmatics of this aforementioned work lies on its interpellating appeal, which is the main function of the essay within Brazilian culture. We conclude that the classificatory dichotomy between science and literature is unsatisfactory to understand the importance the work of Euclides da Cunha had in Brazilian Culture and that the discussions about the genre of Rebellion in the Backlands must focus on the essay. Keywords: Essay form; Euclides da Cunha; Rebellion in the Backlands.

\section{REFERÊNCIAS}

ABREU, Regina. O enigma de Os Sertóes. Rio de Janeiro: Rocco, 1998.

ANDERSON, Benedict. Imagined Communities: Reflections on the Origin and Spread of Nationalism. London: Verso, 1991.

BERNUCCI, Leopoldo. A imitação dos sentidos: Prógonos, contemporâneos e epígonos de Euclides da Cunha. São Paulo: Edusp, 1995.

Prefácio. In: CUNHA, Euclides da. Os Sertóes: Campanha de Canudos. São Paulo: Ateliê Editorial, 2002.

BORGES, Dain. Euclides da Cunha's view of Brazil fractured identity. In: LAUERHASS, Ludwig; NAVA, Carmen (Org). Brazil in the making: facets of national identity. Lanham: Rowman and Littlefield, 2006.

BOURDIEU, Pierre. As regras da arte: Gênese e estrutura do campo literário. Trad. Maria Lucia Machado. São Paulo: Companhia das Letras, 1996.

CANDIDo, Antonio. Euclides da Cunha, sociólogo. Textos de intervenção. São Paulo: Editora 34, 2002.

. Literatura e sociedade. São Paulo: TA Queiroz Editora, 2000.

. Formação da literatura brasileira: Momentos decisivos. 7. ed. Belo Horizonte: Itatiaia, 1997. v. 1.

CARVALHO, José Murilo. Retórica e história intelectual. Prismas, v. 1, n. 2., 1998.

CoUTINHo, Afrânio. Os Sertóes, obra de ficção? Euclides, Capistrano e Araripe. Rio de Janeiro: Edições de Ouro, 1967.

CoutınHo, Carlos Nelson. Cultura e sociedade no Brasil. Rio de Janeiro: Civilização Brasileira, 2000.

CUNHA, Euclides da. Os Sertóes: campanha de Canudos. Edição crítica de Leopoldo Bernucci. São Paulo: Ateliê Editorial, 2002. 
LAMARQUE, Peter; OLSEN, Stein. Truth, Fiction and Literature. New York: Oxford University Press, 1994.

LIMA, Luiz Costa. História. Fiç̧ão. Literatura. São Paulo: Companhia das Letras, 2006.

. D. João VI no Brasil. In: RoCHA, João Cezar de Castro (Org). Nenhum Brasil existe: Pequena enciclopédia. Rio de Janeiro: Topbooks, 2003. 1997. Terra ignota: A construção de Os Sertões. Rio de Janeiro: Civilização Brasileira,

MELLO, Evaldo Cabral de. Reler O Abolicionismo. Um imenso Portugal: História e historiografia. Rio de Janeiro: Editora 34, 2002.

OLIVEIRA, Franklin de. Euclydes, a espada e a letra. Rio de Janeiro: Paz e Terra, 1983.

PROENÇA, Manuel Cavalcanti. Um anfiteatro monstruoso. Estudos literários. Rio de Janeiro: José Olympio, 1971.

RAMOS, Julio. Divergent Modernities: Culture and Politics in Nineteenth-Century Latin America. Trad. John Blanco. Durham: Duke University Press, 2001.

ROCHA, João Cezar de Castro. O exílio do homem cordial. Rio de Janeiro: Museu da República, 2004.

ROMERO, Silvio. Estudos sobre a poesia popular do Brasil. 2. ed. Petrópolis: Vozes, 1977. SCHWARTZ, Lilia Moritz. O espetáculo das raças: Cientistas, instituições e questão racial no Brasil (1870-1930). São Paulo: Companhia das Letras, 1993.

SCHWARZ, Roberto. Um mestre na periferia do capitalismo: Machado de Assis. São Paulo: Editora 34, 2000.

SEVCENKO, Nicolau. Literatura como missão: Tensões sociais e a criação cultural na Primeira República. São Paulo: Editora Brasiliense, 1983.

SEARLE, John. The Logical Status of Fictional Discourse. New Literary History. Baltimore, v 6, n. 2, p. 319-332, 1975.

VENTURA, Roberto. Retrato interrompido da vida de Euclides da Cunha. São Paulo: Companhia das Letras, 2003a.

.Manoel Bomfim:Estados e elites como parasitas do povo-nação. In: ROCHA, João Cezar de Castro (Org). Nenhum Brasil existe: Pequena enciclopédia. Rio de Janeiro: Topbooks, 2003b.

ZILLY, Berthold. A barbárie: antítese ou elemento da civilização? Do Facundo de Sarmiento a Os Sertões de Euclides da Cunha. In: ALMEIDA, Angela; ZILLY, Berthold; LIMA, N de (Org). De sertóes, desertos e espaços incivilizados. Rio de Janeiro: FAPERJ-MAUAD, 2001.

Submetido em: 18/06/2007

Aceito em: 25/11/2008 